\title{
Back to the future: A retrospective assessment of model-based scenarios for the management of the shrimp fishery in French Guiana facing global change
}

\section{Fabian Blanchard $^{1}$ (D) | Christian Chaboud ${ }^{2} \mid$ Olivier Thébaud $^{3}$}

${ }^{1}$ Ifremer, USR LEEISA, CNRS, Université de Guyane, Ifremer, Cayenne Cedex, Guyane française

${ }^{2}$ IRD, UMR MARBEC, IRD, Ifremer, Univ. Montpellier, CNRS, Sète Cedex, France

${ }^{3}$ Ifremer, UMR 6308, AMURE, Ifremer, UBO, CNRS, Unité d'Economie

Maritime, Plouzané Cedex, France

\section{Correspondence}

Fabian Blanchard, Ifremer, USR LEEISA, Université de Guyane, CNRS, Ifremer, 275 Route de Montabo, BP 50477, 97331 CAyenne Cedex, Guyane française. Email: Fabian.Blanchard@ifremer.fr

\section{Funding information}

Agence Nationale de la Recherche, Grant/Award Number: BDIV005; SEAVIEW network funded by the Belmont Forum

\begin{abstract}
While the number of models dedicated to predicting the consequences of alternative resource management strategies has increased, instances in which authors look back at past predictions to learn from discrepancies between these and observed developments are scarce. In the past decades, the French Guiana shrimp fishery has experienced shrimp market globalization and decreasing levels of shrimp recruitment due to environmental changes. In 2006, a bioeconomic model of this fishery was developed to simulate its possible responses to economic and environmental scenarios up to 2016. Here, we compare here these predictions to the observed trajectories. While the number of active vessels corresponds to that which was predicted, the estimated shrimp stock does not. Important driving factors had not been anticipated, including a general strike, natural disasters, and the end of the global financial crisis. These results show the importance of participative approaches involving stakeholders in the co-construction and shared representation of scenarios.
\end{abstract}

\section{Recommendations for resource managers}

- Effective fisheries resources management and a fortiori, the capacity of the fisheries to adapt to global 
change, requires understanding of both ecological and economics dynamics.

- The temporal trajectory of the trawling shrimp fisheries has been well monitored, and the decline of both stock and fleet is understood regarding ecological and economic changes: Changes in the environmental conditions of shrimp recruitment, and oil price increase and selling price decrease.

- However, our bio-economic modeling work showed that, even with a good understanding of the dynamics explaining past trajectories, unpredictable events (strike, natural disasters...) have acted as other key driving factors altering the capacity of the model to represent possible futures.

- These results led us to recommend a better integration of the expertise of social and political scientists in developing models of bio-economic systems to increase the quality of scenario predictions, and to argue for more participative approaches involving the stakeholders.

\section{K E Y W O R D S}

bio-economic model, climate change, numerical simulation, retrospective analysis, seafood market, tropical shrimp fishery, uncertainty

\section{\begin{tabular}{l|l}
1 & INTRODUCTION
\end{tabular}}

Major changes are currently being observed in marine ecosystems and in the human activities that depend on them (Douglas \& McCauley, 2015; Millenium Ecosystem Assessment, 2005). This raises growing concerns, in terms of both the resistance of ecosystems, their capacity to absorb these changes without being radically transformed, and their resilience or capacity to be restored, as well as the sustainability of fisheries that rely on the species they support (Cheung et al., 2009, Cochrane, De Young, Soto, \& Bahri, 2009). There is a need to better understand the adaptive ability of fisheries facing change, and the role of past and future public policies in strengthening or weakening this ability.

Modeling has become an integral part of the scientific toolkit to explore possible futures for natural resource systems, notably marine fisheries (Chaboud, 2014; Thébaud et al., 2014). While the number and diversity of modeling exercises dedicated to predicting the potential ecological, economic, and social outcomes of alternative resource management strategies have been rapidly increasing, instances in which authors look back at past predictions in an attempt to learn from the potential discrepancies between these and observed developments remain scarce. 
Except in the context of formal Management Strategy Evaluation approaches, where deviations between predictions and observations are explicitly incorporated in adaptive, so-called “closed loop" decision rules (Sainsbury, Punt, \& Smith, 2000; Smith, 1994), a large fraction of the literature on model-based scenarios takes a forward-looking perspective only, rarely looking back at past projections. We contend that this lack of retrospective approach precludes potentially important lessons to be learned from past prediction errors, which could inform current and future modeling practices and the way models are used to evaluate and support public policies. This weakens the capacity for model-based scenarios to effectively inform policy. Looking back on past model developments, and confronting forward predictions from simulation models to observed outcomes may provide a number of useful insights regarding both the validity of the models, and potential changes in the dynamics of the fisheries being represented. Such expost evaluations can also play a major role in strengthening the trust that stakeholders (both managers and industry) have in the capacity for models to effectively capture the tradeoffs associated with the management decisions they examine.

Illustrating the value of looking back at past propositions for the future of a fishery system, we consider the example of the French Guiana shrimp fishery. During the past 30 years, this fishery has faced dramatic changes, leading to radical evolutions of its biological and economic status. In 2006, a bio-economic model was built to represent this fishery's dynamics and to test the possible evolution of the fishery facing various scenarios regarding its key economic and environmental drivers (Chaboud, Thébaud, \& Blanchard, 2009). As regards economics, two major driving factors were identified: Shrimp market globalization, with a decreasing trend in real prices, and the long-term increase in real fuel prices worldwide. As regards ecology, recruitment of the two main targeted shrimp species had decreased since 1999, likely due to hydro-climatic modifications linked to global climate change.

The model demonstrated a good capacity to represent past trajectories for fishing effort, production, and stock. Forward-looking simulations were carried out, based on scenarios regarding both ecological and economic drivers. On the economic side, scenarios that were considered rather pessimistic for the industry were used regarding real shrimp prices, fuel price, and the level of public support (subsidies) granted to the fishery. On the ecological side, a moderate hypothesis was chosen regarding the reproduction success of shrimp leading to a recruitment that was assumed to stabilize at low levels. These simulations led to the prediction of a strong decrease in the number of active vessels, from 30 in 2006 to between 15 and 20 in 2016, and to a slight recovery of the stock biomass.

This paper compares the observed trajectories of the key drivers and the observed responses of the French Guiana shrimp fishery to those that had been simulated a decade earlier in 2006. The paper is structured as follows. Section 1 provides a brief introduction to the shrimp fishery and its evolution between the 80s and 2005. Section 2 presents the general characteristics of the simulation model. Section 3 presents the adjustment of the model to historical data (up to 2005) and the predicted trends in the fishery between 2006 and 2016. Section 4 presents the observed trajectories of the driving factors and of the fishery between 2006 and 2014 and discusses these results. Concluding remarks are provided in the last section. 


\section{2 | THE HISTORY OF THE FRENCH GUYANA SHRIMP FISHERY FROM THE 60S TO 2006}

During the 1960s, the US fleet of shrimp trawlers extended their fishing area to the Guiana shelf, from Venezuela to Brazil, to exploit the peneid shrimp stocks. ${ }^{1}$ During nearly 20 years, up to 20,000 tons of shrimps were landed in Cayenne (French Guiana) and Paramaribo (Surinam) by more than 400 US shrimp vessels and sent to the US market. Trawlers from Japan also came to exploit the shrimp stocks in the area. In 1977, the 200 nautical miles Economic Exclusive Zones (EEZ) were established, and the management of marine living resources in the region was placed under the authority of the coastal states, including Venezuela, Guiana, Surinam, France, and Brazil.

During the 1980s, the French state introduced subsidies and invested in coastal infrastructure, to encourage the development of a French shrimp fishing fleet in replacement of foreign fleets still operating in the French EEZ. By 1991, all the US fishing vessels had left, and in 1992, the French fleet had increased to 70 trawlers (Figure 1a). In parallel, the international market for tropical peneid shrimp expanded, probably also contributing to the rapid growth of the French fleet.

However, after 1993, the fishery entered a receding phase, fishing effort constantly decreasing until 2006, while landings were maintained until 1999, before also starting to decrease (Figure 1b). The fleet concentrated its activity in shallow waters, where the F. subtilis biomass was high but mainly composed of juveniles and small adults, with a lower market value, while older, larger shrimps living in deeper offshore areas were less landed. As the variability in recruitment was high, probably due to environmental fluctuations, the exploitation of the young age classes led the fishery to become more dependent on this variability and more vulnerable to low-recruitment levels.

After two periods of socioeconomic crisis in the fishery, in 2000-2001 and 2006, leading to a fleet reduction and vessel ownership concentration, only three fishing firms still remained in the sector, one of them holding more than half the total fishing capacity.

\section{3 | KEY DRIVING FACTORS UP TO 2006}

Combining expertise in ecology, economy, and fisheries management within an integrated research program, we identified three key economic, environmental, and regulatory drivers of the changes observed in the fishery. A first important driving factor was the international shrimp market. Farmed shrimp supply from south-east Asia and Latin America aquaculture exponentially increased at the end of the 1990s, including on the French market where the shrimp from Guyanese trawlers were being sold. This led to a decrease in shrimp world prices, from 7 US \$/kg in 1986 to 6.5 US \$/kg in 2003 (FAO international trade data), and to reduced gross returns from shrimp fishing. Moreover, harvesting costs increased due to the rise in fuel prices. The combined effect of these global trends was a reduction in the competitiveness and profitability of the French Guiana shrimp fishery.

In addition, important ecological drivers were also at play: a Virtual Population Analysis (VPA) carried out by Ifremer and based on monthly data from 1994 to 2006, showed a

${ }^{1}$ Composed mainly of two species Farfantepenaeus subtilis (southern brown shrimp) and F. brasiliensis (pink shrimp) located in the continental shelf of the North Brazil, French Guiana, Suriname, Guyana and the eastern part of Venezuela. 
(a)

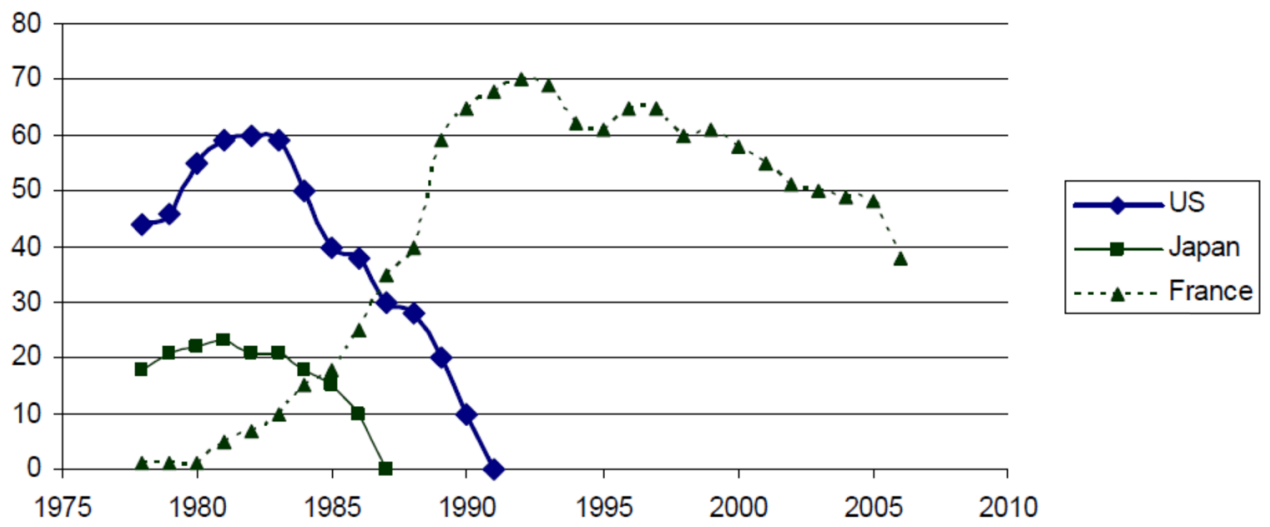

(b)

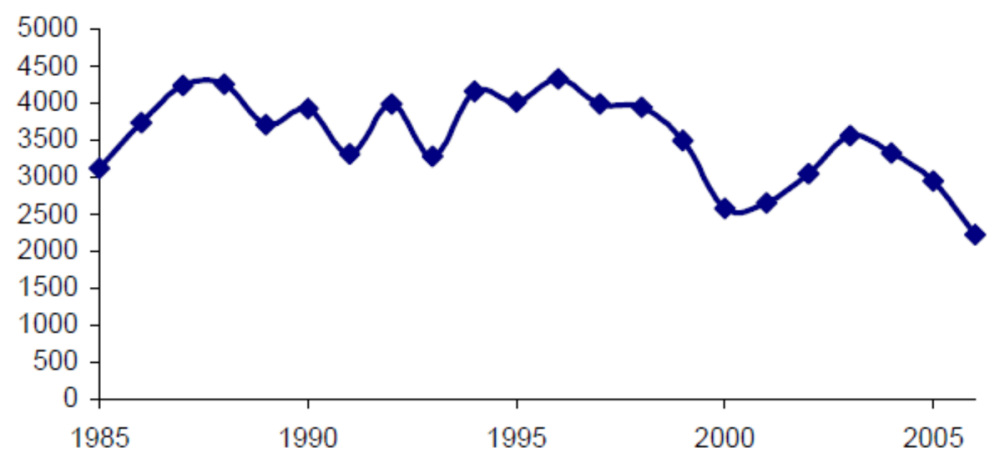

F I G U RE 1 Temporal variation of the number of active vessels, 1978-2006 (a) and total shrimp landings per year in tons, 1985-2006 (b) in the French Guiana shrimp fishery. From Chaboud et al. (2009)

decreasing trend in shrimp recruitment, followed by a decreasing trend in shrimp spawning biomass, after 1995-1996 (Dintheer \& Kalaidjian, 2002). Two periods of low-recruitment for the main target species (F. subtilis): were identified (2000-2001 and 2006). These may have been related to environmental factors, notably the observed increase in sea surface temperatures, and a change in wind regimes (Blanchard \& Thébaud, 2007; Magraoui, Baulier, \& Blanchard, 2014). These environmental changes, likely linked to global climate change, may have induced changes in maturation, fecundity, or larval and/or juvenile mortality parameters of shrimp.

Regulation was also identified as a potentially important driver of the changes observed in the fishery. Some of the European fisheries management tools were implemented in French Guiana after the implementation of an EEZ. In 1983, a total allowable catch (TAC) was established at 4,108 t. The landings, however, were always below this TAC (Figure 7) which was never effectively constraining. France decided to implement free fishing licenses for shrimp trawling in 1991. The initial number of licenses was fixed at 69, and was delivered on an annual basis. However, the number of active shrimp trawlers was always lower than the number of available licenses; hence, as for the TAC, the licence system was never effectively constraining. The minimum mesh size at the cod-end of shrimp trawls was set at $45 \mathrm{~mm}$, allowing small juvenile shrimp to escape. Given the dependence of the stock on recruitment, it was expected that avoiding the catches of small juveniles would allow a significant increase in the stock biomass and in the average size of caught shrimps. Moreover, larger shrimp fetching higher market prices, an increase in the market value of the catch was also anticipated. However, the 
(a)

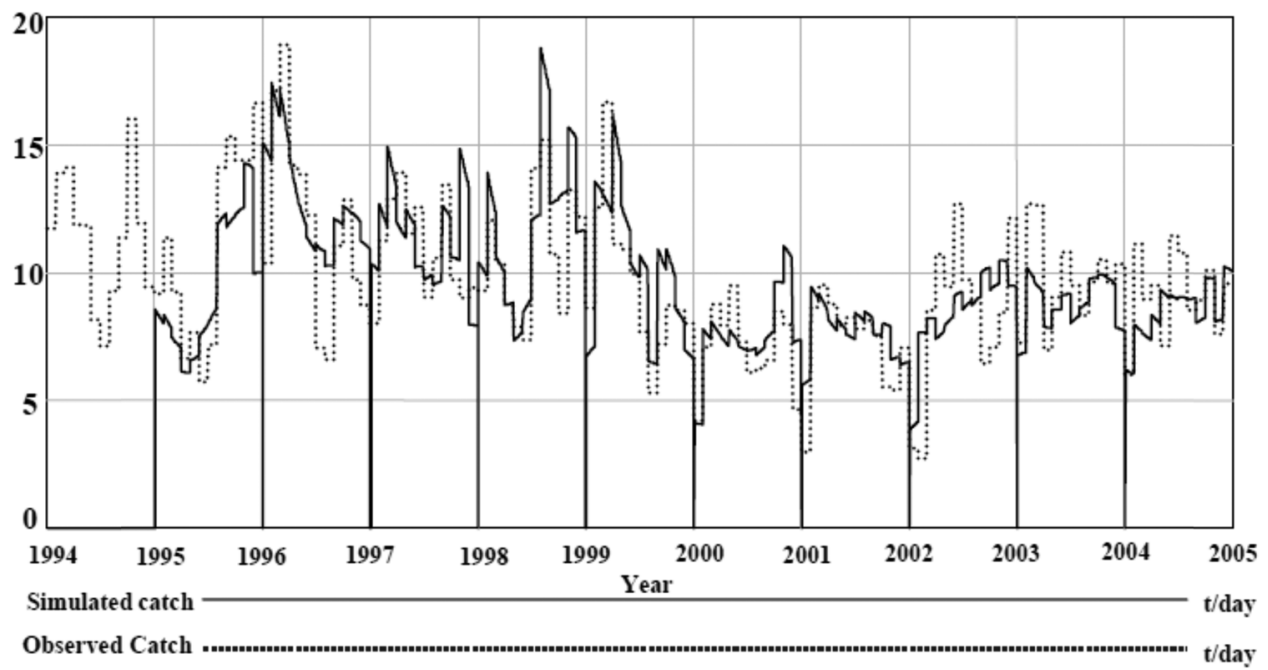

(b)

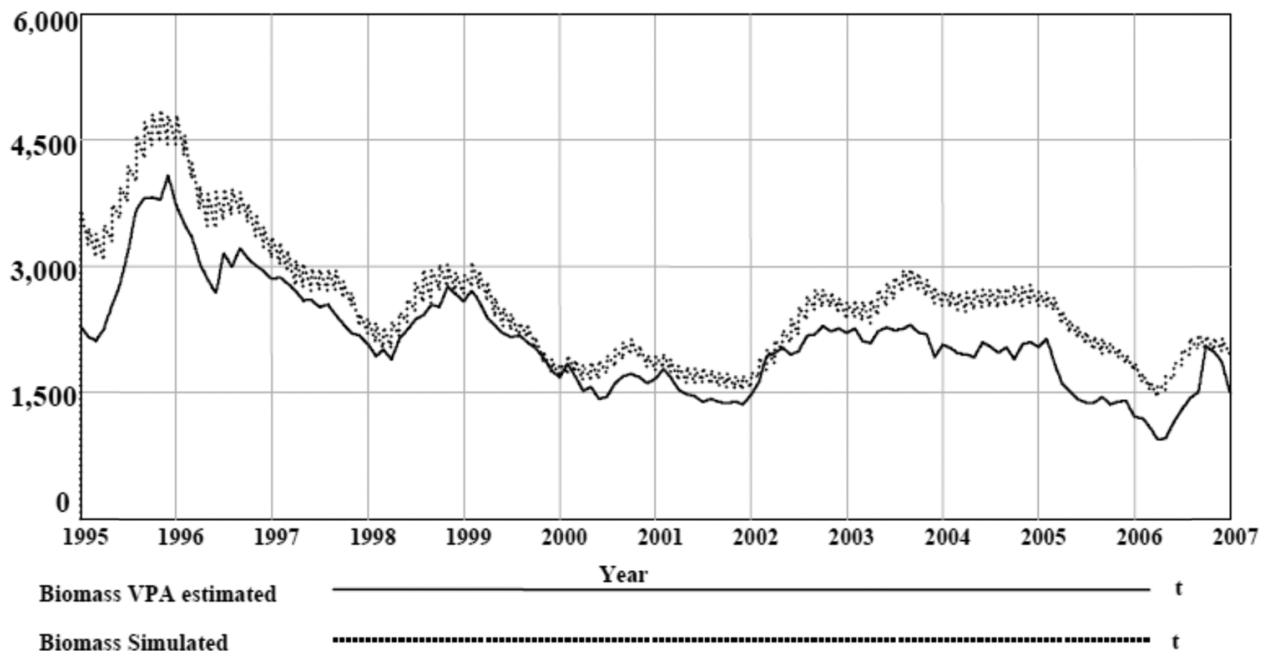

F I G U RE 2 Simulated and observed daily catches (a), and monthly stock biomass (b) of shrimp (From Chaboud et al., 2009, original graphs produced using the Vensim Software)

expected increase in size of the shrimp landed was never observed, as the fleet began to operate in more coastal waters, where juvenile shrimp and young adults live, inducing catches of small individuals (Chaboud et al., 2009).

A trawling ban in coastal waters less than $30 \mathrm{~m}$ in depth was implemented, with two objectives. First, considering the relatively narrow local market for fish products, the ban limited by-catch and landing of commercially-valued coastal fish species by trawlers, thus limiting the economic competition with the coastal small-scale fisheries targeting these species with drift nets. Moreover, the ban protected the juvenile shrimp that live mainly in shallow waters.

French investment in the shrimp trawling fleet was fostered both by the French fiscal regime and by European incentives. In particular, the POSEIDOM program for European outermost 


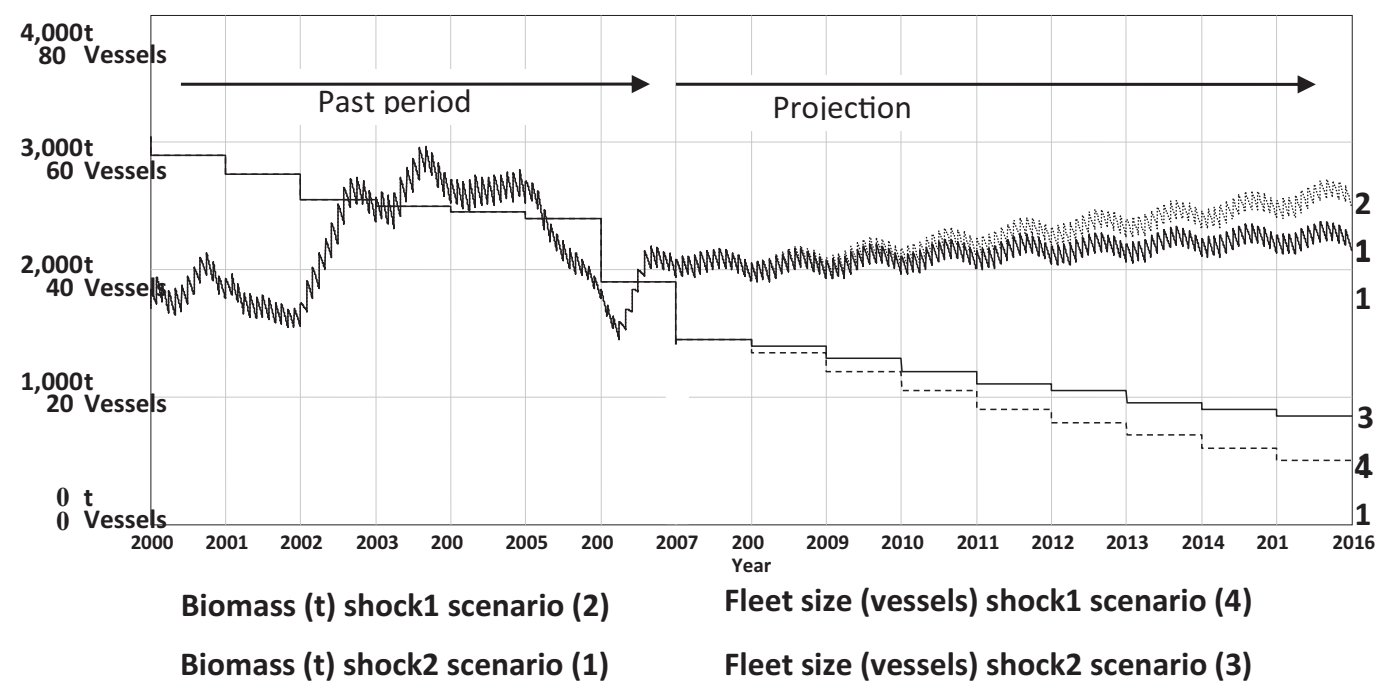

F I G U RE 3 Projections for fleet and biomass, based on the 2004-2007 period of recruitment and scenarios for shrimp and fuel prices, and the European POSEIDOM subsidy (monthly time step, original graphs produced using the Vensim software). Scenario 1, very pessimistic, $4 \%$ decrease per year of shrimp prices for small individuals, $1 \%$ decrease per year for medium-sized shrimp and $2 \%$ increase per year for larger shrimp, 50\% decrease of the POSEIDOM subsidy, and 15\% annual increase in fuel prices. Scenario 2, more optimistic, 3\% per year decrease in shrimp prices for small individuals, no changes in market prices for medium-sized shrimp, and $2 \%$ annual increase in the price of larger shrimps, 25\% decrease of the POSEIDOM subsidy, and 10\% increase in fuel prices

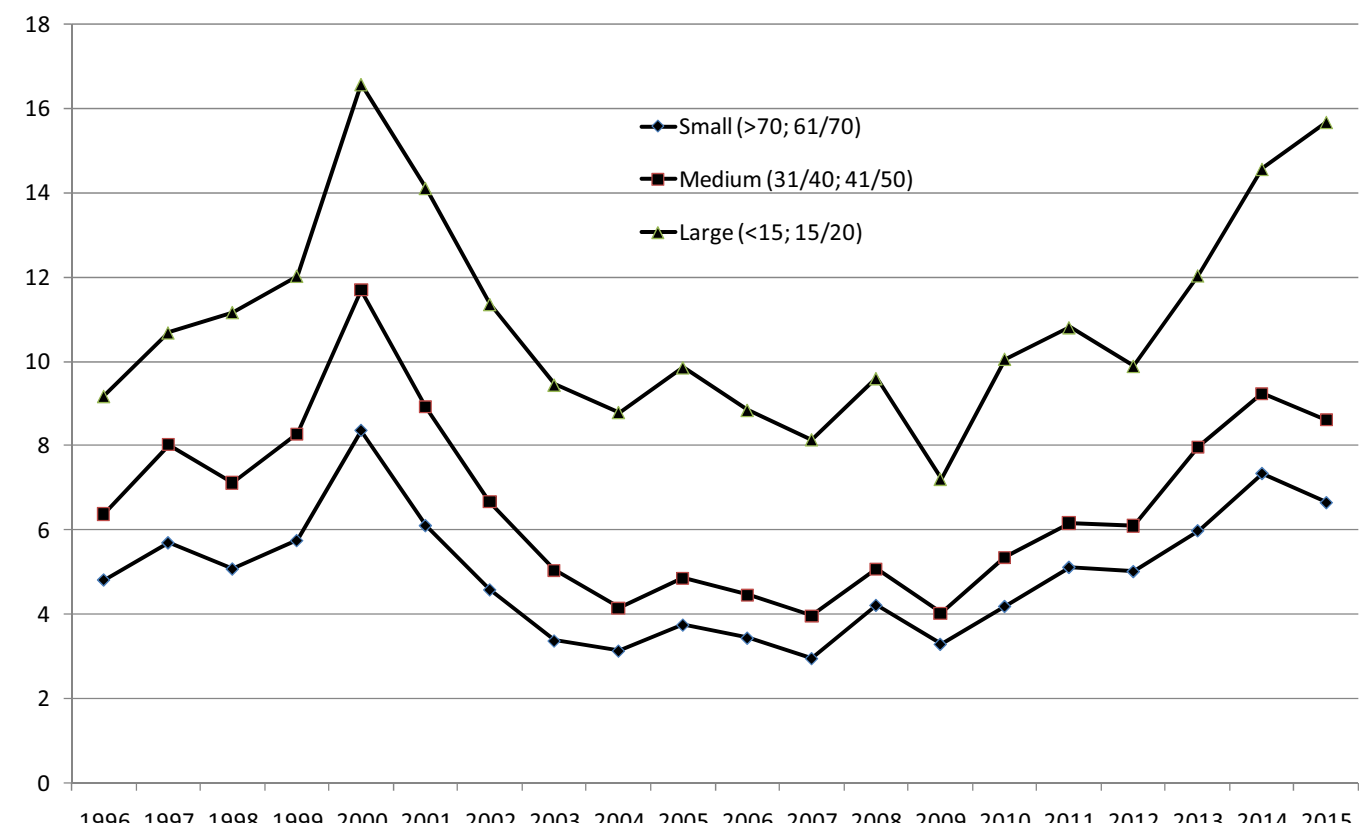

F I G U RE 4 Temporal variations of the shrimp price ( $€$ constant 2005) on the American market 


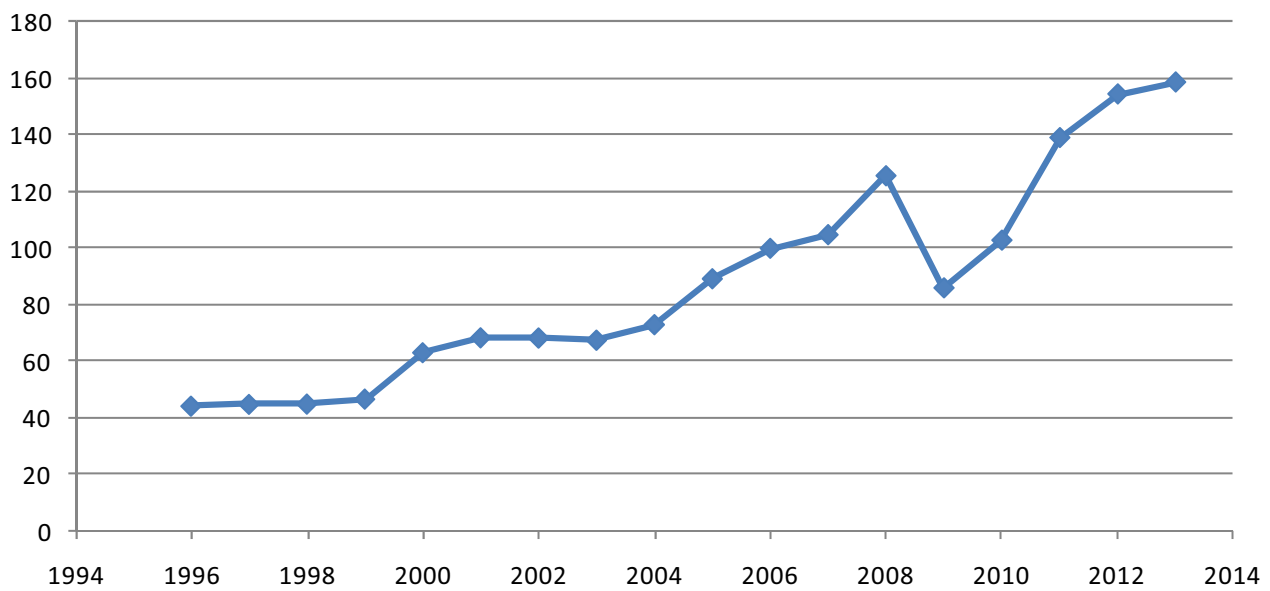

FI G URE 5 Temporal variations of fuel price in French Guiana, base 100 in 2006 (€ constant 2005)

regions (adopted 12/19/1989) was implemented in French Guiana in 1993, to offset the costs induced by its distance to main EU markets. This consisted in a payment of $1.1 €$ per $\mathrm{kg}$ of shrimp exported to the EU market, with a maximum limit of 4,200 $\mathrm{t}$ per year, reduced to 3,300 $\mathrm{t}$ since 2003. This subsidy, granted according to the shrimp landing volume, and not their value, encouraged the fleet to exploit shallow waters where smaller individuals were caught (Chaboud et al., 2009).

Overall, despite scientific reports regarding the degradation of the ecological and economic situation of the fleet, and annual assessments leading to recommendations to reduce the number of licenses and TAC, the management system failed to react and adapt until the late 2000s. In 2008, one fishing firm withdrew nine trawlers from fishing because of economic losses, and the total fleet capacity of the fishery was reduced to 23 fishing units. At the beginning of 2009 the situation had worsened, with only 15 fishing units still actively fishing. The TAC remained unchanged up to 2012. Facing the decline of shrimp recruitment, and consequently, of the spawning biomass, the TAC was reduced to 3,317 tons in 2013 and to 3,100

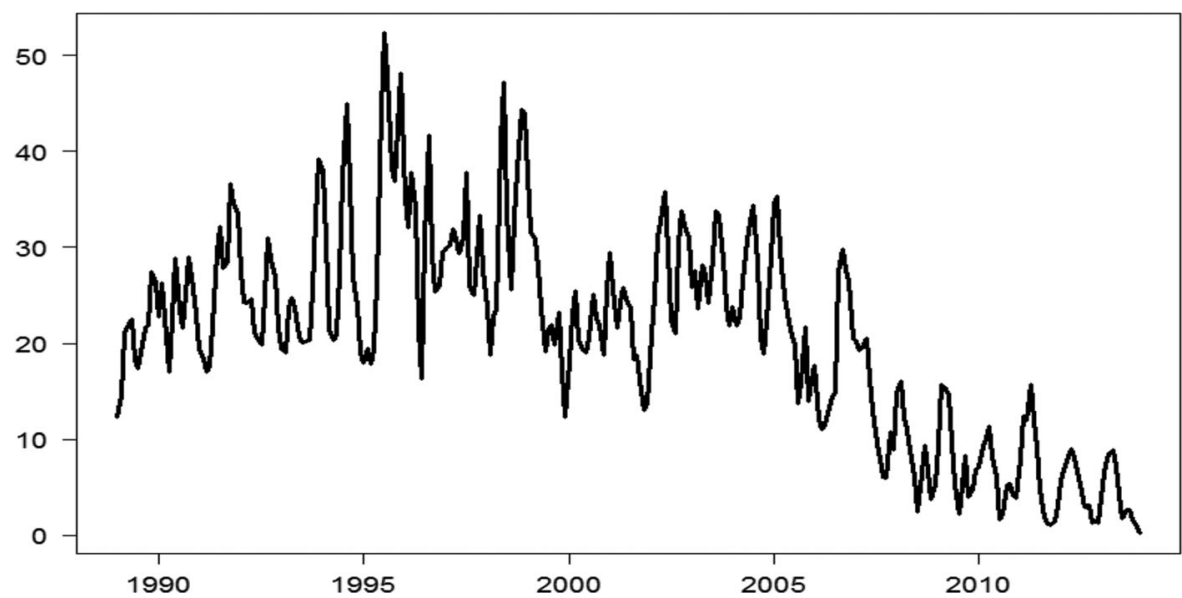

F I G U RE 6 Monthly shrimp recruitment in millions of individuals from VPA analysis. VPA, virtual population analysis 
(a)

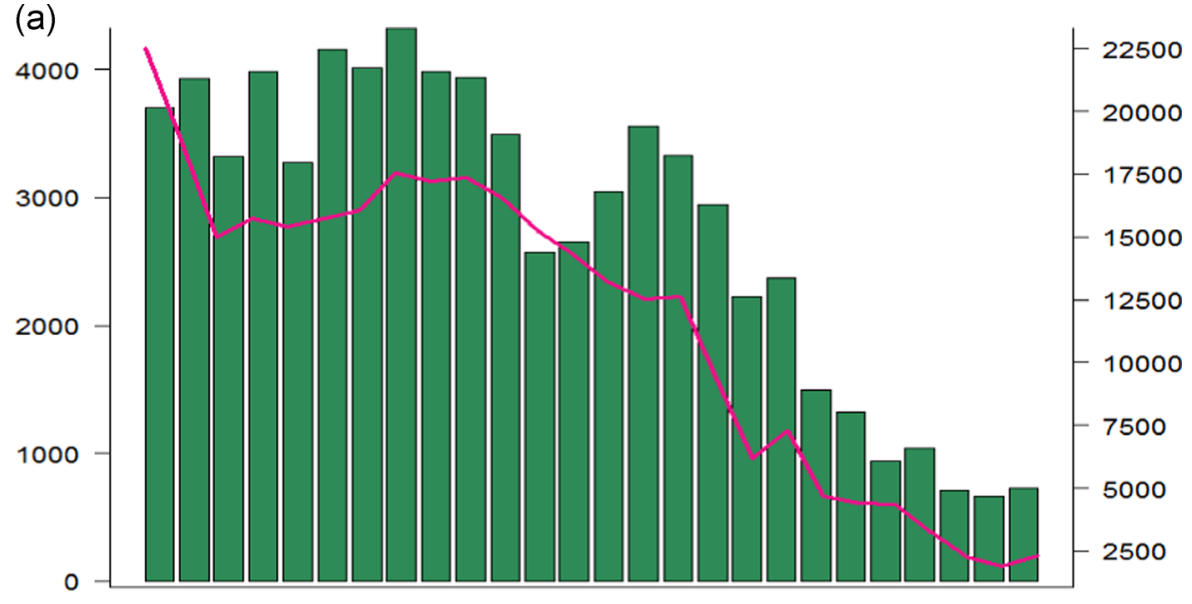

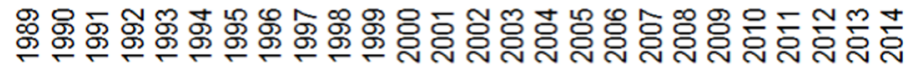

(b)

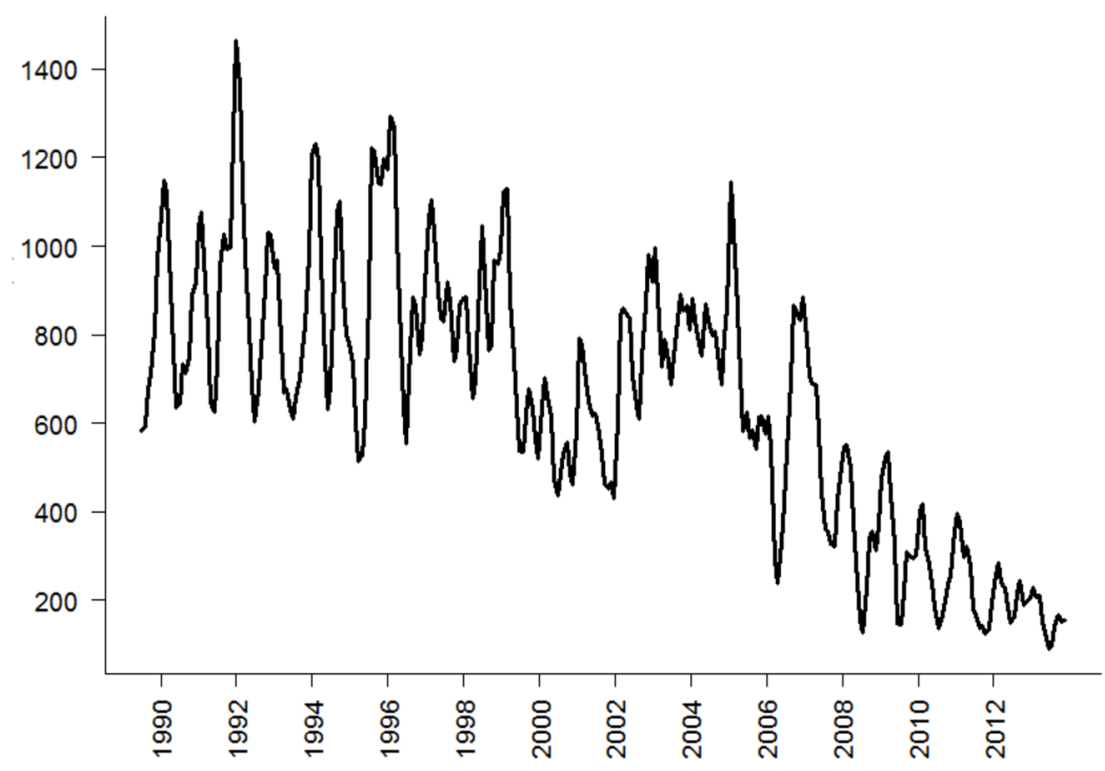

F I G URE 7 (a) Annual landings (t, histogram, left scale) and fishing effort (hours at sea, line, and right scale). (b) Monthly total stock biomass in $t$

tons in 2014. The number of licenses was reduced, in an attempt to adjust the capacity of the fishery to its status, reaching 31 in 2014.

\section{4 | BIO-ECONOMIC MODEL}

The bio-economic model of the French Guiana shrimp fishery was developed with the aim to better understand the trajectory of the fishery over the period 1994-2006 and to enable projections over the following 10 years. The model used an age-structured representation of 
shrimp stocks dynamics, including the two main target species (F. subtilis and F. brasiliensis), with monthly cohorts of males and females. ${ }^{2}$

\subsection{Shrimp abundance and biomass}

Abundances $\mathrm{N}_{\mathrm{t}}$ were computed using:

$$
N_{i, a+1, s}(t+1)=N_{i, a, s}(t) e^{-Z_{i, a, s}(t)}
$$

with $N_{i, a, s}(t)$ the abundance of a cohort of age $a$ of sex $s$ of species $i$ at time $t$, and $Z_{i, a, s}(t)=F_{i, a, s}(t)+M_{i, a, s}(t)$ with $F_{i, a, s}(t)=q_{i, a, s} E(t), q_{i, a, s}$ the catchability coefficient of cohort $a$ of sex $s$ of species $i, M_{i, a, s}(t)$ the natural mortality rate of cohort of age $a$ of sex $s$ of species $i$, and $E(t)$ the fishing effort at time $t$.

Biomass $B_{t}$ was derived from abundance as follows:

$$
B_{i, a, s}(t)=N_{i, a, s}(t) W_{i, a, s}(t)
$$

with $W_{i, a, s}(t)$ the individual weight of shrimp of cohort of age $a$, sex $s$, and species $i$ at time $t$, derived from the weight/length relationship:

$$
W_{i, a, s}(t)=\alpha L C_{i, a, s}^{\beta}(t)
$$

with $L C$ cephalothorax length of shrimp, and $\alpha$ and $\beta$ the allometric parameters, for each species, age, and sex.

\subsection{Catches, revenues, and costs}

Total instantaneous catches were calculated by summing, overall shrimp cohorts, the catch at each time step for each cohort per species and sex. Catches in weight $y_{i, a, s}(t)$ were computed as follows:

$$
y_{i, a, s}(t)=\frac{F_{i, a, s}(t)}{Z_{i, a, s}(t)} B_{i, a, s}(t)\left[1-e^{-Z_{i, a, s}(t)}\right]
$$

Revenue and variable costs were computed at each time step, based on a set of exogenous economic parameters, including shrimp prices per commercial grade of each species, and fixed and variable cost parameters. Catches in value $v_{i, a, s}(t)$ were calculated as follows:

$$
v_{i, a, s}(t)=y_{i, a, s}(t) p_{a}(t)
$$

with $p_{a}(t)$ the price of shrimp of age $a$. The cumulated catches $Y(t)$ and turnover total $V(t)$ for a given year were computed as follows:

${ }^{2}$ In the model, monthly recruitment takes place the first day of each month. 


$$
\begin{aligned}
& Y(\text { year })=\sum_{i, a, s}^{t \in \text { year }} y_{i, a, s}(t) \\
& V(\text { year })=\sum_{i, a, s}^{t \in \text { year }} v_{i, a, s}(t)
\end{aligned}
$$

Total fishing cost TC was calculated as follows:

$$
T C(t)=\left(c_{o i l}(t)+c_{o t h e r}\right) E(t)
$$

With $c_{\text {oil }}$ the cost of fuel per vessel and $c_{\text {other }}$ the other costs (including depreciation costs, material inputs, labor costs, financial expenses, profit tax, and fishing license fees) and $E(t)$ the fishing effort in vessel number.

Net operating income NOI is defined as the yearly sum of the turnover $V_{t}$ minus total fishing costs, plus the European Poseidom incentive calculated as a multiple of the annual total catches:

$$
N O I_{\text {year }}=\sum_{t \in \text { year }}[V(t)-\mathrm{TC}(t)]+s u b_{t} \sum_{t \in \text { year }} Y(t)
$$

\section{3 | Fleet dynamics}

Assuming free entry and exit of vessels in the fishery, ${ }^{3}$ the variation of the number of active vessels at the beginning of each year was assumed to vary as a function of a profitability rate $R_{\text {year }}$ reflecting the previous year's economic results (Smith, 1969). This profitability rate was computed as:

$$
R_{\text {year }}=\frac{N O I_{\text {year }}}{\sum_{t(\text { year })} T C(t)}-C O
$$

with $\mathrm{CO}$, the opportunity cost of capital, arbitrarily set at 0,15 .

The annual variation in fishing effort was thus defined as:

$$
E_{\text {year }+1}=E_{\text {year }}+E_{\text {year }} R_{\text {year }}
$$

and fishing effort per time step in each year $E_{t(\text { year })}$ was set equal to the effort at the beginning of each year $E_{\text {year }}$.

\subsection{Evaluation of management strategies}

This model allowed testing several management options including a change in the number of licenses, or in levels of taxes and subsidies imposed on the fishery, as well as spatial regulations 
and time closures, changes in minimum mesh size, or the implementation of Turtle Excluding Devices (TEDs) and By-catch Reducing Devices (BRDs).

Economic results were calculated at the end of each simulated year and included profit per vessel, total fishery profit, fishery rent, and net contributions from the fishery to State income. Profit was computed incorporating the net contribution of public subsidies to the fishery sector (subsidies less taxes), providing the perspective of private firms on the fishery, while economic rent represented wealth creation from a societal point of view, and was set equal to total profit plus taxes less subsidies.

\section{5 | MODEL CALIBRATION}

The model was calibrated over the 1994-2006 period, using biological and economic data available regarding catches, effort, and size sampling of catches from Ifremer's Fisheries Monitoring System, as well as from direct economic inquiries. For the calibration period, recruitment (estimated from a Virtual Population Analysis) and fishing effort were set equal to the observed historical values. The comparison of the observed and simulated catches over this period showed a relatively good quality of fit (Figure 2a).

The simulated biomass values were compared with the estimated values obtained from a virtual population analysis (VPA). This VPA, for which age structures are inferred from size structures, was carried out yearly to give a recommendation to the French administration in terms of number of licenses and TAC. ${ }^{4}$ Comparison of the biomass estimates with the simulated shrimp biomasses showed a slight over-estimate (Figure $2 b$ ). The quality of fit was better for the most important species ( $F$ subtilis) than for the secondary species (F. brasiliensis).

Finally, the value of landings was computed using the prices observed in 2005 per commercial size category and corrected according to the world trends in shrimp real prices between 1994 and 2006.

\section{6 | SCENARIOS}

The model was used to explore possible responses of the fishery to scenarios of economic and/or ecological change over the 2007-2016 period. In all projections, recruitment was considered as a stochastic variable, and effort as a control variable. Forward simulations assumed recruitment for each species and sex to vary stochastically:

$$
N_{i, 1, s}(t)=\bar{N}_{i, s}+\bar{\varepsilon}_{i, s}(t)
$$

where $\bar{N}_{i, s}$ and $\bar{\varepsilon}_{i, s}(t)$ are the average and variability of recruitment observed for the years 2004-2007. This corresponded to the lowest recorded historical values fo shrimp recruitment (see Section 7).

To assess the potential response of the stock and the fishery to external economic and environmental shocks, two projection scenarios were simulated.

\footnotetext{
${ }^{4}$ The methodology of the VPA used for the shrimp stock assessment is descibed in Lampert L., 2011, Etude de la crise de la pêche de la crevette en Guyane Volume 1: Effets de la pêcherie, hypothèses des causes. RBE/BIODIVHAL 2011-05. https://archimer.ifremer.fr/doc/00075/18584/. For more details about the model implementation and calibration, see Chaboud et al. (2009).
} 


\section{1 | Scenario 1: Very pessimistic}

In the very pessimistic scenario, called scenario 1, we considered a strong decrease of shrimp prices (by $4 \%$ per year for small individuals of commercial categories 40/60 to 120up and by $1 \%$ for medium-sized shrimps of commercial categories $30 / 40^{5}$ ) and an increase by only $2 \%$ per year for larger shrimps (of commercial categories 20/30 and 10/20). Thus, in scenario 1 :

$$
p_{1, a}(t)=\left\{\begin{array}{c}
0,96 p_{a}^{\text {hist }} \text { if } w_{a}<25 \\
0,99 p_{a}^{\text {hist }} \text { if } 25 \leq w_{a} \leq 33 \\
1,2 p_{a}^{\text {hist }} \text { if } w_{a}>33
\end{array}\right.
$$

with $W_{a}$ the weight of shrimp of age a in grams.

In addition, we considered a decrease of the POSEIDOM subsidy by 50\%, consistent with international recommendations for fisheries policy at the time, notably from the World Trade Organization, aimed at reducing trade distortions generated by subsidies:

$$
\operatorname{Sub}_{1}(t)=S u b_{2007} / 2
$$

Finally, a $15 \%$ annual increase in fuel prices was also assumed in this scenario ${ }^{6}$ :

$$
c_{1, \text { oil }}(\text { year })=c_{\text {oil }}(2007) 1,15^{\text {(year-2007) }}
$$

\section{2 | Scenario 2: more optimistic}

In a more optimistic scenario 2, we considered a 3\% per year decrease in shrimp prices for small individuals, no changes in market prices for medium-sized shrimp, and a $2 \%$ annual increase in the price of larger shrimps.

Thus in scenario 2:

$$
p_{2, a}(t)=\left\{\begin{array}{c}
0,97 p_{a}^{\text {hist }} \text { if } w_{a}<25 \\
p_{a}^{\text {hist }} \text { if } 25 \leq w_{a} \leq 33 \\
1,2 p_{a}^{\text {hist }} \text { if } w_{a}>33
\end{array}\right.
$$

In this same scenario, we considered a decrease of the POSEIDOM subsidy by only $25 \%$ :

$$
\operatorname{Sub}_{2}(t)=S u b_{2007} / 2
$$


Fuel prices were set to increase only by $10 \%$ :

$$
c_{2, \text { oil }}(\text { year })=c_{\text {oil }}(2007) 1,15^{\text {(year-2007) }}
$$

\section{7 | PROJECTED FUTURES OF THE FISHERY}

In spite of low-recruitment levels, both scenarios led to a recovery of the shrimp biomass. As explained above, the model assumed that a vessel would exit the fleet when the profit ratio of a vessel becomes negative. The model thus predicted a strong decrease in the number of active boats, from 39 in 2006 to 10 in 2016 under scenario 1, and to 18 under scenario 2. This led to a strong reduction in fishing pressure, allowing the stock to recover (Figure 3).

The simulations suggested that, under these economic and environmental scenarios and with the current management regime, the viability of the fishery would be questioned even with this stock recovery. While the environmental context of the fishery could not be acted upon, management options that were identified as potentially beneficial for the economic viability of the fishery included fishery-wide control of fuel prices (fishers in French Guiana already benefited from price controls on fuel set locally, through tax exemptions), or facilitation of labeling strategies aimed at conquering new niche markets fetching higher sale prices.

\section{OBSERVED TRAJECTORIES BETWEEN 2006 AND 2014}

While the model was not used directly for management, the projected scenarios triggered reflections in the sector regarding the potential benefits of seeking higher value markets. Moreover, the territorial assembly, acknowledging a decrease of the stock, decided to stop the economic support to fleet renewal which the fleet had benefitted from in previous years. A number of changes were observed in the management system after 2006. The implementation of a turtle excluding device (TED) became mandatory in 2010. The TAC was reduced to 3,100 $\mathrm{t}$ in 2014. At the same time, the number of licenses was reduced to 31, but only 29 were allocated and only $764 \mathrm{t}$ of shrimps were produced. Except for TED adoption after 2010, these modifications did not actively drive changes in the fishery over the 2006-2016 period.

The scenarios defined for shrimp prices were a decrease for small shrimps, a slight decrease or stabilization for medium-sized shrimp; and an increase for large shrimp. Observation of price trends on the US market (currently the largest share of the world market) from 2007 to 2015 actually shows an increase by $8-10 \%$ per year for small, medium and large shrimps (Figure 4). In fact, prices decreased up to 2004, remained at stable and low levels up to 2009 and then increased until 2014, up to levels as high as those observed in 2000, before the massive arrival of farmed shrimp on the world market. This inversion in trend may be partly due to renewed economic growth of developing countries after the global financial crisis of 2008, and a reduced growth rate of shrimp production as a result of natural disasters (earthquake, tsunami, droughts, and floods) and diseases (white spot) in the tropical shrimp aquaculture sector in south-east Asian countries (Thitamadee et al., 2016).

It was expected that the European market subsidy (POSEIDOM) would decrease by at least $25 \%$. However, this subsidy actually increased by $25 \%$ in 2014 , to reach 1,385 euros per exported shrimp kilogram. This followed the 2012-2013 preparation of the European Operational 
Programs of support to the fisheries over the 2014-2020 period, when local stakeholders advocated an increase in this subsidy, and its extension to other fish products. This decision was implemented, despite the contemporary international recommendations to eliminate harmful subsidies in marine capture fisheries.

An expected $15 \%$ per year increase in real fuel prices seemed optimistic in comparison with the situation on the world oil market at the time the model was developed. The observed mean yearly local rate of increase was in fact of only $8 \%$ (Figure 5). This was related to social unrest and resulting policy decisions: a general strike occurred in French Guiana in November and December 2008, at the heart of the global financial crisis, with a claim for a 50 eurocent drop of taxes on fuel prices. This was adopted in 2009 via a change in the fuel taxation system, before a new phase of price increase due to international trends in oil prices.

Shrimp recruitment was modeled assuming the average pattern observed during the 2004-2007 period (corresponding to historically low-recruitment levels). However, recruitment continued to decrease, such that even the highest levels of shrimp recruitment effectively observed over the projection period ended up being lower than the lowest levels observed during the 2004-2007 period (Figure 6). Relationships between recruitment and environmental factors were investigated (Magraoui et al., 2014). Marine invertebrates, especially shrimps that are short-lived species, depend on optimal environmental windows for their reproduction. Environmental factors drive the biological dynamics of the individuals which are adapted to mean conditions (mean values of the environmental parameters). These species depend on temperature for growth, survival, maturation, and fecundity. For peneid shrimps, recruitment success may also depend on the intensity and/or direction of the sea surface currents, as eggs are spawn offshore and larvae have to reach the nurseries in shallow waters where they will feed and grow before reaching the adult phase and moving back off-shore. Research showed that sea surface temperature increased, sea surface currents changed and the peak of phytoplankton production (bloom intensity) decreased off the coast of French Guiana over the period of interest. Some new empirical results brought some more evidence of environmental impacts of shrimp stock and production in French Guiana (Sanz et al., 2017; Diop et al., 2018a, 2018b). However, causal relationships between these environmental changes and the evolution of shrimp recruitment have not yet been formally identified.

Overall, observed levels of fishing effort and production strongly decreased over the period 2007-2015 (Figure 7a), and the number of vessels decreased to only 18 active vessels in 2014, as had been predicted by our simulations. However, rather than this leading to an increase in shrimp biomass, the stock continued decreasing due to environmental drivers (Figure 7b), leading to a dire bio-economic situation. Such an outcome was much worse than we had imagined could happen in the most pessimistic of our scenarios.

\section{9 | DISCUSSION}

In French Guiana, stock assessment models (VPA and Y/R) were primarily used to give advice in terms of fishery management (stock and effort). In the early 2000s, according to these models, the stocks were underexploited, while the TAC was not being caught, and the number of effectively used licenses was lower than the maximum number available. Based on this assessment, the advice was that the fishing effort could be increased. However, fishers faced economic difficulties due to decreasing prices of shrimp and increasing operating costs, leading to a decrease in rent and a reduction of the active fleet. Simple model-based advice was not 
followed because this advice was only based on bio-ecological knowledge, ignoring the economic dimensions that fishing companies must also consider. This illustrated the limitations of models that are too simple, and lack relevance for management decision-making. Stakeholders were not convinced by these simple models. This was why a bio-economic model was implemented in $2006 .^{7}$

Increasing model complexity aimed at capturing the combined ecological and economic dynamics of the fishery. The approach provided a tool to better understand the effects of alternative fishing strategies, and to assess the development possibilities for this fishery as well as the conditions under which it could remain viable. Results from the model assuming decreasing selling prices and increasing exploitation costs, together with results from stock assessments showing the negative effects of environmental changes on the stocks, led to identifying a smaller viable number of boats in the fishery. These results were presented at a meeting attended by the managers of the fishery, the industry representatives and the representatives of the territorial assembly in charge of economic development. The leader of a fishing company who attended the meeting stated that the results confirmed the feelings of the industry about the present situation and the potential negative future of the fishery. The fishermen organization suggested that the model be used to test the effects of new management measures such as temporary closures. However, this option was not explored further as the stock problem was attributed to low-recruitment, rather than spawning biomass overexploitation. The main advice eventually produced out of the analysis was the recommendation to explore alternative markets for the shrimp landed by the fleet. Fishing and commercial strategies at the time were based on volume, targeting small sized shrimp in the coastal area, and producing low value products. A quality-based strategy, targeting larger sizes, and higher value shrimp would have allowed increased individual boat rents. To reduce the ecological footprint of shrimp trawling, turtle and large-fish excluding devices were implemented and became mandatory in 2010. This was expected to enable access to eco-labeled markets, with potentially higher selling prices. However, on-board shrimp processing practices precluded the production of high-quality shrimp. Significant investments would have been required to adapt vessels to alternative processing practices, but despite what appeared to be a shared understanding of this, the investments have not been undertaken. This also led the territorial assembly to remove existing economic support towards fleet renewal, judging that the risk for such support to be ineffective was too high. ${ }^{8}$

Despite a reasonably good understanding of the exploited resource dynamics and of the economics of shrimp fishing, the results of this ex-post evaluation of bio-economic predictions for the future of the French Guiana shrimp fishery show that such predictions heavily depended on the scenarios we used for key biological and economic parameters corresponding to alternative possible states of the world. Our analysis demonstrates the importance of these scenarios in developing forward-looking assessments of alternative management strategies for marine capture fisheries. Simulation-based predictions can be extremely sensitive to what are often termed "external forcing factors," or "key drivers," which are usually not explicitly modeled at a fishery level. A key challenge thus rests in the way in which assumptions regarding these key drivers can be developed and verified. In the case of the French Guiana shrimp fishery, this proved important in relation to social and economic dimensions, as well as

\footnotetext{
${ }^{7}$ As part of a research project called "CHALOUPE", funded by the French National Research Agency.

${ }^{8}$ Moreover, within the framework of the new Common Fishery Policy, economic support towards fleet renewal was forbidden, although the European Commission allowed this again in 2018 for outermost regions of the European Union.
} 
environmental dimensions. While modeling can seek to integrate greater complexity as for example regarding the dynamics of fish recruitment in relation to environmental drivers, or the dynamics of shrimp prices on the world market, our analysis also points to the existence of events that will be difficult to predict, notably social responses leading to political decisions that modify the economic conditions under which a fishery operates. A possible way forward is to explore stochastic versions of the models, with uncertainty included in both the economic (subsidies, fuel and shrimp prices) and the ecological (recruitment, individual growth, and natural mortality) dimensions of the processes at play. This approach would provide envelopes of possible trajectories rather than only one for a given scenario, but often quickly encounters the limitations of computing power. An alternative would be to explore multiple scenarios including extreme variations in certain components of the system. For instance, recruitment could be decreased at various rates, linearly, or with threshold effects. Shrimp prices could be decreased or increased with various rates, linearly, or with threshold effects. Fuel costs could increase or decrease at various rates. Finally, ecological (recruitment) or economic shocks (price, incentive, and cost) could be simulated on the panel of scenarios. The most important and difficult aspect of in designing these scenarios is likely to envisage extreme changes, particularly those that go against the most recently observed trends. With increased uncertainty, we would also probably find trajectories, or envelopes of trajectories filling all the possibility space, with totally opposite trajectories becoming possible depending on the scenarios. The risk could then be to give stakeholders the feeling that science is unable to assist in identifying the more likely futures, and the extent to which current decisions are likely to enable achieving desired states for the fishery.

\section{CONCLUSION}

Many years ago, an important distinction was made by economists, Knight (1921), and later Keynes (1936), between risk and uncertainty. Risk can be estimated by probabilities inferred by the observation of past events. On the contrary uncertainty is related to rare or singular events. This distinction still seems relevant today. Objective probability analysis is not sufficient to support our attempts to explore the uncertain future of bio-economic systems. In our modeling experience, our hypotheses concerning external economic or environmental shocks and public policies were unable to represent the likelihood of uncertain events that proved key in the observed changes of the fishery. Such events actually modified the trajectories of the drivers in ways that biologists and economists had not been able to predict. This highlights a need to revisit the ways in which models are often produced and used. Models, with their inherent limitations, may be all the more useful if they are used for the co-construction of scenarios with stakeholders, to better take into account local economic and political responses (Etienne, 2011) to a broad spectrum of external shocks. There is growing evidence from participatory research exercises that the early strategic engagement of stakeholders in the research process allows developing more effective projections (Chakraborty, 2011; Macher et al., 2018). In addition to projections based on recent trends, co-constructing shared representations of the possible futures of a bio-economic system (seen as in Schwartz (1996) as perceptions about alternative future environments) should also seek to identify extreme scenarios, and the more probable trajectories under each of these, using the expertise of a representative panel of researchers and stakeholders. Such a participative approach would increase the legitimacy of model scenarios for managers and fishermen, as well as the associated management recommendations. Our 
results also point to the strong possibility for surprises in complex systems (Batty \& Torrens, 2005), such as in fisheries management, and a need for adaptive capacity, including in the use of modeling and assessment frameworks, to cope with unplanned changes. Finally, considering the nature of the surprises that needed to be addressed in French Guiana (i.e., a strike and the associated political lobbying to maintain subsidies), we contend that we can increase the quality of our scenario predictions by integrating the expertise of social and political scientists in developing models of bio-economic systems. This concurs with the general support for more comprehensive approaches and multidisciplinary teams to better understand socio-ecological systems (Link et al., 2017; Österblom et al., 2013).

\section{ACKNOWLEDGMENTS}

This study was funded by the French National Agency for Research, as part of the Chaloupe program. The ex-post evaluation has been carried out under the framework of the SEAVIEW network funded by the Belmont Forum. We thank two anonymous reviewers and the Associate Editor of NRM for their advice which allowed to significantly improve the manuscript.

\section{ORCID}

\section{Fabian Blanchard (D) http://orcid.org/0000-0001-8496-877X}

\section{REFERENCES}

Batty, M., \& Torrens, P. M. (2005). Modelling and prediction in a complex world. Futures, 37, 745-766.

Blanchard, F., \& Thébaud, O. (2007), Changement global, dynamique de la biodiversité marine exploitée et viabilité des pêcheries, In: Actes des 5e journées de l'IFB, 3-6 décembre 2007, Tours: 20-24.

Chaboud, C. (2014). Fisheries economics. In A. Monaco, \& P. Prouzet (Eds.), Value and economy of marine resources, ISTE (pp. 153-231). Hoboken: J. Wiley and Sons, London.

Chaboud, C., Thébaud, O., \& Blanchard, F. (2009). In R. S. Anderssen, R. D. Braddok, \& L. T. H. Newham (Eds.), Bioeconomic model of the dynamics of fisheries facing global economic and environment changes. The French Guiana shrimp fishery model (2009 Canberra (AUS), Bruxelles: MSSANZ, IMACS. 18th World IMACS/ MODSIM Congress, Cairns, Australia 13-17 July 2009.

Chakraborty, A. (2011). Enhancing the role of participatory scenario planning processes: Lessons from reality check exercises. Futures, 43, 387-399.

Cheung, W. W. L., Lam, V. W. Y., Sarmiento, J. L., Kearney, K., Watson, R., Zeller, D., \& Pauly, D. (2009). Large scale redistribution of maximum fisheries catch potential on the global ocean under climate change. Global Change Biology, 16, 24-35.

Cochrane, K., De Young, C., Soto, D., \& Bahri, T. (2009). Climate change implications for fisheries and aquaculture. Roma: FAO. Fao, Fisheries and Aquaculture technical paper (530).

Dintheer, C., \& Kalaidjian, R. (2002). Expertise sur la situation de la pecherie crevettiere guyanaise, 2000-2001. Convention DPMA/Ifremer (réf. Ifremer 01/1214037F).

Diop, B., Blanchard, F., \& Sanz, N. (2018b). Mangrove increases resiliency of the French Guiana shrimp fishery facing global warming. Ecological Modelling, 387, 27-37.

Diop, B., Sanz, N., Duplan, J., Guene, M., Blanchard, F., Pereau, J.-C., \& Doyen, L. (2018a). Maximum economic yield fishery management in the face of global warming. Ecological Economics, 154, 52-61.

Douglas, J., \& McCauley (2015). Marine defaunation: Animal loss in the global ocean. Science, 347.

Etienne, M. (2011), Companion modeling, a participatory approach supporting sustainable development, Quae.

Keynes, J. M. (1936). The general theory of employment, interest and money. Macmillan.

Knight, F. (1921). Risk and uncertainty and profit. Boston: Houghton and Mifflin. 
Link, J. S., Thebaud, O., et al. (2017). Keeping humans in the ecosystem. ICES Journal of Marine Science, 74(7), 1947-1956.

Macher, C., Bertignac, M., et al. (2018). The role of technical protocols and partnership engagement in developing a decision support framework for fisheries management. Journal of Environmental Management, 223, 503-516.

Magraoui, A., Baulier, L., \& Blanchard, F. (2014), Effet du changement climatique sur le stock guyanais de crevettes pénéïdes, Rapport final du projet PENECLIM, DPMA-Ifremer.

Millenium Ecosystem Assessment. (2005). Ecosystems and human well-being. Washington, DC: Island, Press.

Sanz, N., Diop, B., Blanchard, F., \& Lampert, L. (2017). On the influence of environmental factors on harvest: The French Guiana shrimp fishery paradox. Environmental Economics And Policy Studies, 19(2), $233-247$.

Sainsbury, K. J., Punt, A. E., \& Smith, A. D. M. (2000). Design of operational management strategies for achieving fishery ecosystem objectives. ICES Journal of Marine Science, 57, 731-741.

Schwartz, P. (1996). The art of the long view: Planning for the Future in an Uncertain World (p. 292). Paperback Edition.

Smith, A. D. M. (1994). Management strategy evaluation, the light on the hill. In D. A. Hancock (Ed.), Population Dynamics for Fisheries Management (pp. 249-253). Perth: Australian Society for Fish Biology.

Smith, V. L. (1969). On models on commercial fishing. J Pol Econ, 77, 181-198.

Thitamadee, S. A., Prachumwat, A., Srisala, J., Jaroenlak, P., Salachan, P. V., Sritunyalucksana, K., ... Itsathitphaisam, O. (2016). Review of current disease threats for cultivated shrimp in Asia. Aquaculture, 42, 69-87.

Thébaud, O., Innes, J., Doyen, L., Lample, M., Macher, C., Mahevas, S., ... Vermard, Y. (2014). Building ecological-economic models and scenarios of marine resource systems: Workshop report. Marine Pollution, 43, 382-386.

Österblom, H., Merrie, A., Metian, M., Boonstra, W. J., Blenckner, T., Watson, J. R., ... Folke, C. (2013). Modeling social-ecological scenarios in marine systems. BioScience, 63, 735-744.

How to cite this article: Blanchard F, Chaboud C, Thébaud O. Back to the future: A retrospective assessment of model-based scenarios for the management of the shrimp fishery in French Guiana facing global change. Natural Resource Modeling. 2019;e12232. https://doi.org/10.1111/nrm.12232 